\title{
Prognostic utility of heart-type fatty acid-binding protein in patients with stable coronary artery disease and impaired glucose metabolism: a cohort study
}

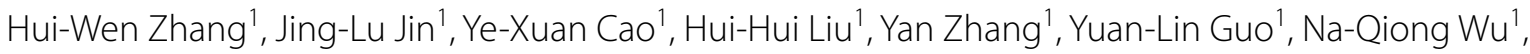 \\ Ying Gao' ${ }^{1}$ Rui-Xia Xu' ${ }^{1}$ Qi Hua ${ }^{2}$, Yan-Fang Li ${ }^{3}$, Chuan-Jue Cui ${ }^{1}$, Geng Liu' ${ }^{1}$, Qian Dong ${ }^{1}$, Jing Sun ${ }^{1}$ \\ and Jian-Jun $\mathrm{Li}^{1 *}$ (B)
}

\begin{abstract}
Background: Heart-type fatty acid-binding protein (H-FABP) is a novel marker of myocardial injury and has been reported to be associated with cardiovascular diseases (CVD) including patients with diabetes mellitus (DM). Unfortunately, its prognostic value in patients with CVD and impaired glucose metabolism (IGM) is unclear. The objective of this study was to investigate the prognostic value of H-FABP in CVD patients with IGM.

Methods: A total of 4594 patients with angiography-proven coronary artery disease (CAD) were enrolled and divided into subgroup according to glucose metabolism status (normal glucose regulation [NGR], pre-DM, and DM). Baseline levels of H-FABP were measured using latex immunoturbidimetric method. The cardiovascular events (CVE) were defined as cardiovascular death, myocardial infarction, stroke and coronary revascularization. Cox regression and Kaplan-Meier analysis were used to evaluate the relations of H-FABP and glucose metabolism status to CVEs.

Results: During the follow-up period with up to 7.1 years, 380 CVEs occurred. Patients with CVE had higher levels of H-FABP compared to those without CVE $(p<0.001)$. Interestingly, H-FABP levels were also elevated in DM and pre-DM groups compared with NGR group ( $p<0.001)$, when combined glucose metabolism status with H-FABP stratification, patients in the highest tertile of H-FABP appeared to have higher risk of CVEs with pre-DM (adjusted hazard ratio [HR]: 1.855, 95\% confidential intervals [Cls] 1.076-3.214; $p=0.033$ ) and DM (adjusted HR: 2.560, 95\% Cls 1.409-4.650; $p=0.002$ ). The Kaplan-Meier curve indicated that DM patients with the highest H-FABP levels were associated with the greatest risk of CVEs $(p<0.05)$.
\end{abstract}

Conclusions: Our data firstly showed that elevated H-FABP levels were associated with worse outcomes in CAD patients with pre-DM and DM, which provided the novel information that H-FABP might be a prognostic marker for clinical outcomes among patients with CAD and IGM.

Keywords: Heart-type fatty acid-binding protein, Impaired glucose metabolism, Coronary artery disease

*Correspondence: 13901010368@163.com; lijianjun938@126.com 1 State Key Laboratory of Cardiovascular Disease, Fu Wai Hospital, National Center for Cardiovascular Diseases, Chinese Academy of Medical Sciences and Peking Union Medical College, No 167 BeiLiShi Road, XiCheng District, Beijing 100037, China

Full list of author information is available at the end of the article

\section{Background}

It is well known that diabetes mellitus (DM) is a type of metabolic disease closely correlated with classic cardiovascular risk factors, such as obesity, hypertension, and dyslipidemia. Consequently, patients with DM are

(c) The Author(s) 2020. This article is licensed under a Creative Commons Attribution 4.0 International License, which permits use, sharing, adaptation, distribution and reproduction in any medium or format, as long as you give appropriate credit to the original author(s) and the source, provide a link to the Creative Commons licence, and indicate if changes were made. The images or other third party material in this article are included in the article's Creative Commons licence, unless indicated otherwise in a credit line to the material. If material is not included in the article's Creative Commons licence and your intended use is not permitted by statutory regulation or exceeds the permitted use, you will need to obtain permission directly from the copyright holder. To view a copy of this licence, visit http://creativeco mmons.org/licenses/by/4.0/. The Creative Commons Public Domain Dedication waiver (http://creativecommons.org/publicdomain/ zero/1.0/) applies to the data made available in this article, unless otherwise stated in a credit line to the data. 
commonly complicated with higher risk of cardiovascular disease [1-3]. Pre-diabetes mellitus (pre-DM) is an intermediate status between normal glucose regulation (NGR) and DM, which is initially considered as a condition associated with the development of DM [4-6]. Recently, the attention for pre-DM has significantly been attracted due to its higher risk for coronary artery disease (CAD) and adverse cardiovascular events (CVE) [7-11]. Additionally, besides the atherosclerosis of large arteries can be easily induced by impaired glucose metabolism (IGM), previous studies have also provided the evidence supporting the relation of IGM to myocardial injury and silent ischemia among patients with IGM [12-14]. Furthermore, previous studies have also revealed that diabetic patients might suffer from cardiac dysfunction due to its complications such as diabetic cardiomyopathy or diabetic vasculopathy $[15,16]$.

Heart-type fatty acid binding protein (H-FABP), a novel cardiac marker, has been used as a diagnostic indicator of acute myocardial injury [17-19]. Previous studies have shown that H-FABP is not only a predictor of acute myocardial infarction (AMI) and adverse clinical events [19-22], but of other conditions as well. For example, series of studies have demonstrated that H-FABP elevated in patients with hypertension, dilated cardiomyopathy, heart failure, stroke, and pulmonary embolism [23-27]. Recently, plasma H-FABP levels were also found to be higher in diabetic patients, even in prediabetic status when compared with general population $[13,14,28]$. Akbal et al. [13] reported that serum H-FABP levels were significantly higher in diabetic patients with metabolic syndrome (MetS) than those without diabetic MetS. Besides, Basak et al. [28] found that H-FABP levels were increased in patients with IGM, and were positively correlated with carotid artery intima-media thickness (an intermediate phenotype for early atherosclerosis). Although the underlying mechanism of elevated H-FABP levels in relation to cardiac injury in patients with IGM is unclear, these data suggested that H-FABP might be a novel alternative index for detecting myocardial damage and early atherosclerosis, even a prognostic marker of future outcome in diabetic patients. The aim of the present study, therefore, was to investigate the role of $\mathrm{H}$-FABP levels in predicting clinical outcomes in CAD patients with IGM.

\section{Methods}

\section{Study population}

From November 2011 to February 2017, 6778 consecutive patients underwent coronary angiography (CAG) because of angina-like chest pain and/or positive treadmill exercise test or clinically suspected CAD were enrolled from three medical centers. The study flowchart was shown as Fig. 1. Patients without H-FABP data or informed written consents, and patients with severe infectious or systematic inflammatory diseases, severe liver and renal insufficiency, significant hematologic disorders, and thyroid dysfunction were excluded. Finally, a total of 4594 patients were enrolled in analysis.

DM was diagnosed as fasting plasma glucose $\geq 7.0 \mathrm{mmol} / \mathrm{L}$, the 2 -h plasma glucose of the oral glucose tolerance test $\geq 11.1 \mathrm{mmol} / \mathrm{L}$, or current therapy of hypoglycemic drugs or insulin. Pre-DM was defined as participants without self-reported DM or hypoglycemic treatment but with fasting plasma glucose ranging from 5.6 to $6.9 \mathrm{mmol} / \mathrm{L}, 2$-h glucose ranging from 7.8 to $11.0 \mathrm{mmol} / \mathrm{L}$, or hemoglobin A1c (HbA1c) level ranging from 5.7 to $6.4 \%$. Then patients without DM or pre-DM were diagnosed as NGR [4]. Hypertension was defined as repeated systolic blood pressure $\geq 140 \mathrm{mmHg}$ or diastolic blood pressure $\geq 90 \mathrm{mmHg}$ ( $\geq$ three times), or self-reported hypertension, current antihypertensive treatments. Information of other disease history was collected from self-reported medical history. The body mass index (BMI) was calculated as weight $(\mathrm{kg})$ divided by height (m) squared. The kidney function was measured as estimated glomerular filtration rate (eGFR) using Chronic Kidney Disease Epidemiology Collaboration (CKDEPI) equation: $141 \times \min (\mathrm{SCr} / \kappa, \quad 1)^{\alpha} \times \max (\mathrm{SCr} / \kappa$, $1)^{-1.209} \times 0.993^{\mathrm{Age}} \times 1.018$ [if female] $\times 1.159$ [if Black] [29]. CAD was defined as the presence of coronary stenosis $\geq 50 \%$ at least one major artery segment assessed by two experienced physicians according to the results of CAG as mentioned in our previous studies [10]. The severity of coronary stenosis was assessed as Gensini Score (GS) system, which was defined as 1-point for $<25 \%$ stenosis, 2-point for $26-50 \%$ stenosis, 4-point for $51-75 \%$ stenosis, 8-point for $76-90 \%$ stenosis and 32 -point for total occlusion. Then the score was multiplied by a factor that represents the importance of the lesion's position in the coronary arterial system.

The CVEs included cardiovascular death, non-fatal myocardial infarction (MI), stroke, and coronary revascularization (CRV). Non-fatal MI was diagnosed as typical chest pain with positive cardiac troponins or typical changes of electrocardiogram serial. Stroke was diagnosed by the presence of typical symptoms and cerebral imaging examination. CRV included coronary percutaneous coronary artery intervention and/ or bypass grafting. The participants were followed up at 6 -months intervals by methods of interview or telephone conducted by trained physicians or nurses who were blinded to the clinical data. 


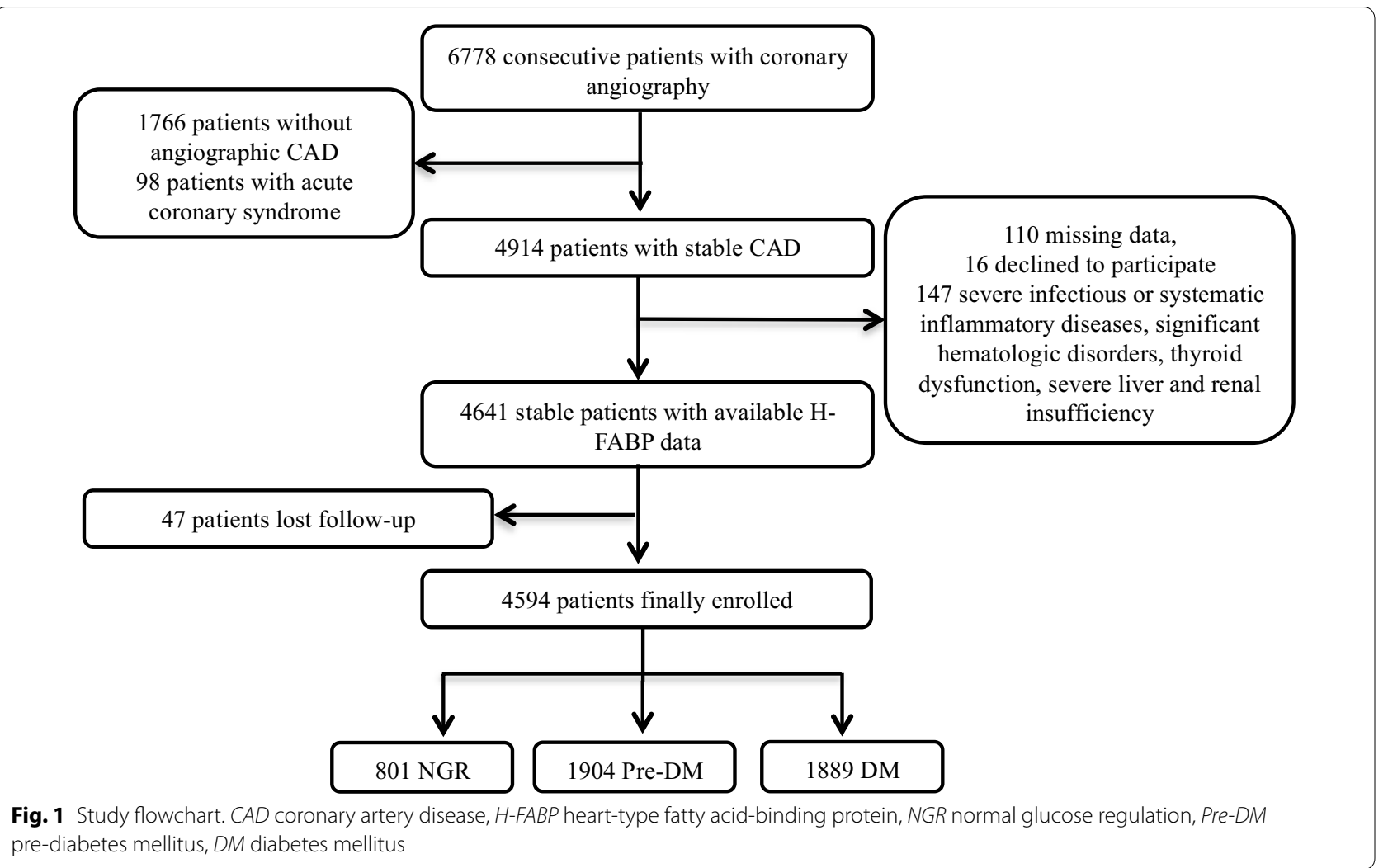

\section{Statistical analysis}

Mean \pm standard deviation (SD) or median (inter-quartile range) was expressed for continuous data, and the qualitative data was shown as frequencies or percentage (n, $\%)$. Chi square test was used to compare the categorical data. T-test was performed for the normally distributed data to determine differences among groups. As for nonnormally distributed data, the Mann-Whitney $U$ test was performed for comparison between two-groups and the Kruskal-Wallis test was used for comparison of multigroups as appropriate. Then we used a Cox proportional hazards analysis to explore the group differences among different levels of H-FABP and status of glucose metabolism. Finally, the event-free survival rates of CVEs among the subgroups according to H-FABP levels diabetic status were conducted by the Kaplan-Meier method and then compared by the log-rank test. Our statistical analyses were performed using SPSS software version 23.0 (SPSS, Inc., Chicago, IL, USA). The differences were considered significant if $\mathrm{p}<0.05$ in two-sided tests.

\section{Laboratory analysis}

The venous blood samples were taken from each patient after a $12 \mathrm{~h}$ overnight fasting to collect baseline laboratory data prior to coronary intervention. Lipid profiles were determined by automatic biochemistry analyzer
(Hitachi 7150, Tokyo, Japan). Detailed, total cholesterol (TC) and triglyceride (TG) were analyzed by enzymatic methods. Low-density lipoprotein cholesterol (LDL-C) concentration was determined by selective solublilization method (low-density lipid cholesterol test kit; Kyowa Medex, Tokyo). High-density lipoprotein cholesterol (HDL-C) concentration was measured by a homogeneous method (Determiner L HDL; Kyowa Medex, Tokyo). The concentrations of glucose were measured by enzymatic hexokinase method. Hemoglobin A1c (HbA1c) was measured using the Tosoh Automated Glycohemoglobin Analyzer (HLC-723G8). Plasma H-FABP levels were measured by Latex Immunoturbidimetric Method. This turbidometric immunoassay was performed using the Hitachi 7180 chemistry analyzer (reference interval $<5 \mathrm{ng} / \mathrm{mL}$ ).

\section{Results}

\section{Baseline characteristics}

The baseline characteristics were provided in Table 1. A total of 4594 patients with stable CAD were finally included in our study, the mean age of participants was $58.2 \pm 9.9$ years and $3266(71.9 \%)$ patients were male. According to the levels of H-FABP, patients were divided into 3 subgroups as Tertile $1(<1.80 \mathrm{ng} / \mathrm{mL}$, $\mathrm{n}=1685)$, Tertile $2(1.80-2.70 \mathrm{ng} / \mathrm{mL}, \mathrm{n}=1452)$, and 
Table 1 Baseline characteristics of patients with different H-FABP levels

\begin{tabular}{|c|c|c|c|c|c|}
\hline Variables & Total $(\mathrm{N}=4594)$ & Tertile $1(\mathrm{~N}=1685)$ & Tertile $2(\mathrm{~N}=1452)$ & Tertile $3(N=1457)$ & $p$ value for trend \\
\hline \multicolumn{6}{|l|}{ Baseline characteristics } \\
\hline Age (years) & $58.2 \pm 9.9$ & $54.7 \pm 9.1$ & $58.4 \pm 9.2$ & $62.0 \pm 9.7$ & $<0.001$ \\
\hline Male (n, \%) & $3266(71.9 \%)$ & $1206(71.6 \%)$ & $1041(71.7 \%)$ & $1019(69.9 \%)$ & 0.499 \\
\hline BMI $\left(\mathrm{kg} / \mathrm{m}^{2}\right)$ & $25.92 \pm 3.14$ & $25.82 \pm 2.98$ & $25.91 \pm 3.08$ & $26.06 \pm 3.36$ & 0.114 \\
\hline Hypertension (n, \%) & $3005(65.4 \%)$ & $1041(61.8 \%)$ & $917(63.2 \%)$ & $1047(71.9 \%)$ & $<0.001$ \\
\hline Dyslipidemia (n, \%) & $4147(90.3 \%)$ & $1520(90.2 \%)$ & $1323(91.1 \%)$ & $1304(89.5 \%)$ & 0.337 \\
\hline Diabetes $(n, \%)$ & $1889(41.1 \%)$ & $618(36.7 \%)$ & $566(39.0 \%)$ & $705(48.4 \%)$ & $<0.001$ \\
\hline Current smokers $(n, \%)$ & $1438(31.3 \%)$ & $548(32.5 \%)$ & $468(32.2 \%)$ & $422(29.0 \%)$ & 0.065 \\
\hline Peripheral vascular disease $(\mathrm{n}, \%)$ & $59(1.3 \%)$ & $16(0.9 \%)$ & $19(1.3 \%)$ & $24(1.6 \%)$ & 0.222 \\
\hline Cerebrovascular disease $(\mathrm{n}, \%)$ & $145(3.2 \%)$ & $44(2.6 \%)$ & $46(3.2 \%)$ & $55(3.8 \%)$ & 0.177 \\
\hline Family history of CAD (n, \%) & $643(14.0 \%)$ & $258(15.3 \%)$ & $198(13.6 \%)$ & $187(12.8 \%)$ & 0.122 \\
\hline \multicolumn{6}{|l|}{ Laboratory data } \\
\hline Triglyceride (mmol/L) & $1.80 \pm 1.23$ & $1.82 \pm 1.32$ & $1.80 \pm 1.15$ & $1.78 \pm 1.22$ & 0.581 \\
\hline $\mathrm{TC}(\mathrm{mmol} / \mathrm{L})$ & $4.14 \pm 1.17$ & $4.15 \pm 1.20$ & $4.13 \pm 1.09$ & $4.14 \pm 1.20$ & 0.929 \\
\hline LDL-C (mmol/L) & $2.51 \pm 0.99$ & $2.53 \pm 1.08$ & $2.51 \pm 0.93$ & $2.48 \pm 0.95$ & 0.260 \\
\hline HDL-C (mmol/L) & $1.05 \pm 0.29$ & $1.05 \pm 0.29$ & $1.06 \pm 0.29$ & $1.06 \pm 0.29$ & 0.506 \\
\hline Glucose (mmol/L) & $6.20 \pm 2.04$ & $6.12 \pm 2.00$ & $6.16 \pm 1.99$ & $6.33 \pm 2.13$ & 0.016 \\
\hline $\mathrm{HbA1c}(\%)$ & $6.54 \pm 1.24$ & $6.42 \pm 1.22$ & $6.50 \pm 1.17$ & $6.72 \pm 1.30$ & $<0.001$ \\
\hline Creatinine $(\mu \mathrm{mol} / \mathrm{L})$ & $77.97 \pm 17.30$ & $74.17 \pm 13.98$ & $76.23 \pm 14.62$ & $84.10 \pm 21.16$ & $<0.001$ \\
\hline eGFR (mL/min/1.73 m²) & $93.74 \pm 9.12$ & $97.38 \pm 8.07$ & $94.09 \pm 8.09$ & $89.16 \pm 9.24$ & $<0.001$ \\
\hline \multicolumn{6}{|l|}{ Treatments in hospital } \\
\hline Aspirin $(n, \%)$ & $4462(97.1 \%)$ & $1637(97.2 \%)$ & 1410 (97.1\%) & 1415 (97.1\%) & 0.997 \\
\hline$\beta$-Blokers (n, \%) & $3417(78.3 \%)$ & $1335(79.2 \%)$ & $1133(78.0 \%)$ & $1129(77.5 \%)$ & 0.477 \\
\hline Lipid-lowering mediation (n, \%) & 4269 (92.9\%) & $1551(92.0 \%)$ & $1348(92.8 \%)$ & $1370(94.0 \%)$ & 0.096 \\
\hline ACEl or ARB $(n, \%)$ & $2157(47.0 \%)$ & $714(42.4 \%)$ & 669 (46.1\%) & $774(53.1 \%)$ & $<0.001$ \\
\hline Gensini score & $34.50 \pm 32.07$ & $32.42 \pm 30.33$ & $33.70 \pm 30.44$ & $37.72 \pm 35.24$ & $<0.001$ \\
\hline Events (n, \%) & $380(8.3 \%)$ & 100 (5.9\%) & $121(8.3 \%)$ & 159 (10.9\%) & $<0.001$ \\
\hline
\end{tabular}

Values are expressed as the mean \pm SD or $\mathrm{n}(\%)$. Italic values indicate statistical significance

$C A D$ coronary artery disease, $B M I$ body mass index, NGR normal glucose regulation, Pre-DM pre-diabetes mellitus, $D M$ diabetes mellitus, $T C$ total cholesterol, $L D L-C$ low-density lipoprotein cholesterol, $H D L-C$ high-density lipoprotein cholesterol, $H b A 1 c$ glycated hemoglobin $A 1 c, H-F A B P$ heart-fatty acid binding protein, $A C E I$ angiotensin converting enzyme inhibitors, $A R B$ angiotensin receptor blocker, eGFR estimated glomerular filtration rate

Tertile $3(>2.70 \mathrm{ng} / \mathrm{mL}, \mathrm{n}=1457)$. Data suggested that patients with higher H-FABP levels were older compared to those with lower H-FABP levels, but there was no significant difference in gender distribution with different H-FABP levels. In addition, patients with higher H-FABP levels had more frequent hypertension, diabetes as well as higher glucose, HbA1c, creatinine and lower eGFR levels $(\mathrm{p}<0.05$, respectively) compared to the lower ones. Moreover, we found that patients with elevated H-FABP levels showed increased Gensini score and incidence of CVEs $(5.9 \%$ vs $8.3 \%$ vs $10.9 \%$, $\mathrm{p}<0.001)$. Overall, $380(8.3 \%)$ CVEs occurred including 77 cardiovascular deaths, 49 non-fatal MI, 92 stroke and 162 CRV as shown in Additional file 1: Table S1. Notably, serum H-FABP levels were significantly elevated in event patients compared with non-event ones (mean: $2.95 \mathrm{ng} / \mathrm{mL}$ vs $2.41 \mathrm{ng} / \mathrm{mL}, \mathrm{p}<0.001$ ).
Meanwhile, patients with events were older, hypertensive and more likely to be current smokes $(p<0.05$, respectively). In persons with events, there were higher level of glucose and HbA1c when compared with those without events $(\mathrm{p}<0.05$, respectively). There was no significant difference in family history of CAD, dyslipidemia and baseline treatments in hospital between the two groups (all $\mathrm{p}>0.05$ ).

In Table 2, patients were divided into three subgroups as NGR $(\mathrm{n}=801,17.4 \%)$, pre-DM $(\mathrm{n}=1904,41.4 \%)$ and DM ( $\mathrm{n}=1889,41.1 \%)$. Across all three conditions, patients with pre-DM and DM were older, had higher $\mathrm{BMI}$, and higher rate of hypertension and dyslipidemia (all $\mathrm{p}<0.05$ ) but less to be male and current smokers as compared with controls. H-FABP levels were significantly higher in the subjects with pre-DM and DM compared with those in NGR group $(\mathrm{p}<0.001)$. Baseline glucose and HbA1c were lower in the controls as compared with 
Table 2 Baseline characteristics according to status of glucose metabolism

\begin{tabular}{|c|c|c|c|c|c|}
\hline Variables & Total $(\mathrm{N}=4594)$ & NGR $(N=801)$ & Pre-DM $(\mathrm{N}=1904)$ & $\mathrm{DM}(\mathrm{N}=1889)$ & $p$ value for trend \\
\hline \multicolumn{6}{|l|}{ Baseline characteristics } \\
\hline Age (years) & $58.2 \pm 9.9$ & $55.2 \pm 9.9$ & $58.3 \pm 9.5$ & $59.3 \pm 9.7$ & $<0.001^{*}$ \\
\hline Male (n, \%) & $3266(71.9 \%)$ & $617(77.0 \%)$ & $1346(70.7 \%)$ & $1303(69.0 \%)$ & $<0.001^{*}$ \\
\hline BMI $\left(\mathrm{kg} / \mathrm{m}^{2}\right)$ & $25.92 \pm 3.14$ & $25.51 \pm 3.01$ & $25.69 \pm 2.96$ & $26.38 \pm 3.42$ & 0.006 \\
\hline Hypertension (n, \%) & 3005 (65.4\%) & $461(57.6 \%)$ & $1200(63.0 \%)$ & $1344(71.1 \%)$ & $<0.001$ \\
\hline Dyslipidemia (n, \%) & $4147(90.3 \%)$ & $701(87.5 \%)$ & 1745 (91.6\%) & $1701(90.0 \%)$ & $0.004^{*}$ \\
\hline Current smokers $(n, \%)$ & $1438(31.3 \%)$ & $332(41.4 \%)$ & $704(37.0 \%)$ & $402(21.3 \%)$ & $<0.001$ \\
\hline Peripheral vascular disease $(n, \%)$ & $59(1.3 \%)$ & $6(0.7 \%)$ & $18(0.9 \%)$ & $35(1.9 \%)$ & 0.015 \\
\hline Cerebrovascular disease $(\mathrm{n}, \%)$ & $145(3.2 \%)$ & $24(3.0 \%)$ & $60(3.2 \%)$ & $61(3.2 \%)$ & 0.951 \\
\hline Family history of CAD $(n, \%)$ & $643(14.0 \%)$ & $137(17.1 \%)$ & $255(13.4 \%)$ & $251(13.3 \%)$ & $0.020^{*}$ \\
\hline \multicolumn{6}{|l|}{ Laboratory data } \\
\hline Triglyceride (mmol/L) & $1.80 \pm 1.23$ & $1.67 \pm 1.14$ & $1.73 \pm 1.00$ & $1.93 \pm 1.46$ & $<0.001$ \\
\hline $\mathrm{TC}(\mathrm{mmol} / \mathrm{L})$ & $4.14 \pm 1.17$ & $4.03 \pm 1.03$ & $4.19 \pm 1.17$ & $4.14 \pm 1.22$ & $<0.001^{*}$ \\
\hline LDL-C (mmol/L) & $2.51 \pm 0.99$ & $2.45 \pm 1.01$ & $2.54 \pm 0.97$ & $2.50 \pm 0.95$ & 0.284 \\
\hline $\mathrm{HDL}-\mathrm{C}(\mathrm{mmol} / \mathrm{L})$ & $1.05 \pm 0.29$ & $1.07 \pm 0.31$ & $1.08 \pm 0.30$ & $1.03 \pm 0.28$ & 0.001 \\
\hline Glucose (mmol/L) & $6.20 \pm 2.04$ & $4.79 \pm 0.42$ & $5.32 \pm 0.65$ & $7.69 \pm 2.41$ & $<0.001^{*}$ \\
\hline HbA1c (\%) & $6.54 \pm 1.24$ & $5.37 \pm 0.24$ & $5.05 \pm 0.26$ & $7.64 \pm 1.23$ & $<0.001^{*}$ \\
\hline $\mathrm{H}-\mathrm{FABP}(\mathrm{ng} / \mathrm{mL})$ & $2.45 \pm 1.86$ & $2.10 \pm 1.13$ & $2.41 \pm 1.71$ & $2.64 \pm 2.21$ & $<0.001^{*}$ \\
\hline Creatinine $(\mu \mathrm{mol} / \mathrm{L})$ & $77.97 \pm 17.30$ & $78.55 \pm 16.28$ & $78.40 \pm 18.94$ & $77.29 \pm 15.95$ & 0.532 \\
\hline eGFR (mL/min/1.73 m²) & $93.74 \pm 9.12$ & $95.77 \pm 8.87$ & $93.80 \pm 8.64$ & $92.81 \pm 9.56$ & $<0.001^{*}$ \\
\hline \multicolumn{6}{|l|}{ Treatments in hospital } \\
\hline Aspirin $(n, \%)$ & $4462(97.1 \%)$ & $776(96.9 \%)$ & $1861(97.7 \%)$ & $1825(96.6 \%)$ & 0.103 \\
\hline$\beta$-Blokers $(n, \%)$ & $3417(78.3 \%)$ & $595(74.3 \%)$ & $1466(77.0 \%)$ & $1536(81.3 \%)$ & $<0.001$ \\
\hline Lipid-lowering mediation (n, \%) & $4269(92.9 \%)$ & $731(91.3 \%)$ & $1786(93.8 \%)$ & $1752(92.7 \%)$ & 0.058 \\
\hline ACEI or ARB (n, \%) & $2157(47.0 \%)$ & $334(41.7 \%)$ & 877 (46.1\%) & $946(50.1 \%)$ & $<0.001$ \\
\hline Gensini score & $34.50 \pm 32.07$ & $30.94 \pm 28.02$ & $32.16 \pm 29.54$ & $38.38 \pm 35.56$ & $<0.001$ \\
\hline Events (n, \%) & $380(8.3 \%)$ & $45(5.6 \%)$ & $125(6.6 \%)$ & $210(11.1 \%)$ & $<0.001$ \\
\hline
\end{tabular}

Values are expressed as the mean \pm SD or $\mathrm{n}(\%)$. Italic values indicate statistical significance. *Indicate statistical significance between NGR and Pre-DM

$C A D$ coronary artery disease, $B M I$ body mass index, $T C$ total cholesterol, $L D L-C$ low-density lipoprotein cholesterol, $H D L-C$ high-density lipoprotein cholesterol, $H b A 1 C$ glycated hemoglobin A1c, H-FABP heart-fatty acid binding protein, $A C E I$ angiotensin converting enzyme inhibitors, $A R B$ angiotensin receptor blocker, $N G R$ normal glucose regulation, Pre-DM pre-diabetes mellitus, DM diabetes mellitus, eGFR estimated glomerular filtration rate

both groups of pre-DM and DM. Additionally, HDL-C cholesterol was lower and TG, TC levels were higher in subjects with IGM (all $\mathrm{p}<0.05$ ). The serum creatinine levels did not differ significantly in the three groups $(\mathrm{p}=0.532)$ but eGFR were decreased in patients with IGM compared to ones in NGR group $(\mathrm{p}<0.001)$. Importantly, diabetic patients had higher Gensini score compared with the controls $(\mathrm{p}<0.001)$. In total cohort, not surprisingly, patients in DM group had more than 1.5 times increased incidence of CVE compared with NGR group $(11.1 \%$ vs $5.6 \%, \mathrm{p}<0.001)$ but no difference in the occurrence of CVEs between NGR and pre-DM group (5.6\% vs $6.6 \%$, $\mathrm{p}>0.05)$.

\section{H-FABP, glucose metabolism and events}

The relationship between H-FABP, glucose metabolism and CVEs was explored by stratifying the patients into subgroups according to the tertiles of H-FABP and glucose metabolism status. As shown in In Additional file 1: Table S2, data from the Cox proportional-hazards model indicated that the highest tertile of H-FABP levels were associated with increased risk of CVEs [unadjusted hazard ratios (HR): 1.670; 95\% confidence intervals (CIs) 1.299-2.146, $\mathrm{p}<0.001]$. After adjustment of age, gender, hypertension, dyslipidemia, BMI, current smoking, family history of CAD, Gensini score and eGFR, the results retained (adjusted HR: 1.335; 95\% CIs 1.011-1.762, $\mathrm{p}=0.041)$. With regard to the glucose metabolism, only patients in DM group showed association with CVEs at HR with 1.608 (95\% CIs 1.151-2.248, $\mathrm{p}=0.005$ ).

Next, we performed subgroups analysis to further explore the correlation between pre-DM, DM and H-FABP with CVEs. As listed in Table 3, in unadjusted model, both patients with pre-DM and DM in the highest tertile of H-FABP showed positive association with CVEs and these findings persisted in adjusted models 
Table 3 H-FABP levels in relation to cardiovascular events in patients with pre-DM and DM

\begin{tabular}{|c|c|c|c|c|}
\hline \multirow[t]{2}{*}{ IGM } & \multicolumn{4}{|l|}{ HRs (95\% Cls) } \\
\hline & Unadjusted & $p$ value & Adjusted $^{\mathrm{a}}$ & $p$ value \\
\hline \multicolumn{5}{|l|}{ Pre-DM } \\
\hline Tertile 1 & Reference & - & Reference & - \\
\hline Tertile 2 & $1.206(0.762-1.908)$ & 0.424 & $0.971(0.556-1.234)$ & 0.728 \\
\hline Tertile 3 & $1.864(1.203-2.890)$ & 0.005 & $1.335(1.059-1.772)$ & 0.039 \\
\hline \multicolumn{5}{|l|}{ DM } \\
\hline Tertile 1 & Reference & - & Reference & - \\
\hline Tertile 2 & $1.142(0.820-1.608)$ & 0.628 & $1.012(0.795-1.423)$ & 0.772 \\
\hline Tertile 3 & $1.631(1.161-2.362)$ & 0.021 & $1.322(1.035-1.730)$ & 0.040 \\
\hline
\end{tabular}

Italic values indicate statistical significance

Pre-DM pre-diabetes mellitus, $D M$ diabetes mellitus, $H$ - $F A B P$ heart-type fatty acid-binding protein, HRs hazard ratios, Cls confidential intervals

a Adjusted for age, gender, hypertension, dyslipidemia, body mass index, current smoking, family history of CAD and Gensini score, eGFR

in pre-DM patients (HR: 1.335, 95\% CIs 1.059-1.772, $\mathrm{p}=0.039$ ) and DM patients (HR: 1.322 , 95\% CIs $1.035-$ 1.730, $\mathrm{p}=0.040)$. Additionally, we further investigate the relationship between IGM and H-FABP with CVEs by combining the status of glucose metabolism with H-FABP stratification. Hence, the patients were divided into 9 subgroups. In Table 4, the Cox regression analysis after adjustment for the confounders according to both glucose metabolism and H-FABP status indicated that patients with pre-DM plus the highest tertile of H-FABP levels showed 1.855-fold higher risk of CVE (95\% CIs $1.076-3.214, \mathrm{p}=0.033)$ compared with the reference group (NGR plus Tertile 1 of H-FABP). What's more, patients in DM group had significantly increased risk of CVEs compared with the reference group (NGR plus Tertile 1 of H-FABP) in all tertiles of H-FABP (Tertile 1: adjusted HR: 2.131, 95\% CIs 1.157-3.925, $\mathrm{p}=0.015$; Tertile 2: adjusted HR: 2.171, 95\% CIs 1.179-3.997, $\mathrm{p}=0.013$; Tertile 3: adjusted HR: 2.560 , 95\% CIs 1.409_ 4.650, $\mathrm{p}=0.002)$.

Finally, we performed the Kaplan-Meier curves for the subgroups according to the H-FABP tertiles and glucose metabolism status as shown in Fig. 2. Figure 2a demonstrated that patients with DM were associated with the higher risk of adverse events. Notably, the Kaplan-Meier curves demonstrated that patients with DM in the highest $\mathrm{H}$-FABP group were associated with the greatest risk of CVEs (Fig. 2b).

\section{Discussion}

As compared with what we known about H-FABP, a novel biomarker for myocardial injury in CAD, little is known about its prognostic value for patients with
Table 4 H-FABP levels in relation to cardiovascular events in patients with different glucose metabolism status

\begin{tabular}{|c|c|c|c|c|}
\hline \multirow{2}{*}{$\begin{array}{l}\text { Glucose } \\
\text { metabolism } \\
\text { status }\end{array}$} & \multicolumn{4}{|l|}{ HRs (95\% Cls) } \\
\hline & Unadjusted & $p$ value & Adjusted $^{a}$ & $p$ value \\
\hline \multicolumn{5}{|l|}{$N G R$} \\
\hline Tertile 1 & Reference & - & Reference & - \\
\hline Tertile 2 & $\begin{array}{l}2.101(0.998- \\
4.215)\end{array}$ & 0.053 & $\begin{array}{l}2.016(0.994- \\
4.088)\end{array}$ & 0.052 \\
\hline Tertile 3 & $\begin{array}{l}1.563(0.713- \\
3.427)\end{array}$ & 0.265 & $\begin{array}{l}1.347(0.611- \\
2.967)\end{array}$ & 0.460 \\
\hline \multicolumn{5}{|l|}{ Pre-DM } \\
\hline Tertile 1 & $\begin{array}{l}1.303(0.696- \\
2.477)\end{array}$ & 0.418 & $\begin{array}{l}1.211(0.635- \\
2.439)\end{array}$ & 0.448 \\
\hline Tertile 2 & $\begin{array}{l}1.498(0.802- \\
2.796)\end{array}$ & 0.205 & $\begin{array}{l}1.395(0.748- \\
2.579)\end{array}$ & 0.312 \\
\hline Tertile 3 & $\begin{array}{l}2.382(1.295- \\
4.382)\end{array}$ & 0.005 & $\begin{array}{l}1.855(1.076- \\
3.214)\end{array}$ & 0.033 \\
\hline \multicolumn{5}{|l|}{ DM } \\
\hline Tertile 1 & $\begin{array}{l}2.590(1.413- \\
4.746)\end{array}$ & 0.002 & $\begin{array}{l}2.131(1.157- \\
3.925)\end{array}$ & 0.015 \\
\hline Tertile 2 & $\begin{array}{l}2.755(1.511- \\
5.023)\end{array}$ & 0.001 & $\begin{array}{l}2.171(1.179- \\
3.997)\end{array}$ & 0.013 \\
\hline Tertile 3 & $\begin{array}{l}3.529(1.976- \\
6.302)\end{array}$ & $<0.001$ & $\begin{array}{l}2.560(1.409- \\
4.650)\end{array}$ & 0.002 \\
\hline
\end{tabular}

Italic values indicate statistical significance

NGR normal glucose regulation, Pre-DM pre-diabetes mellitus, DM diabetes mellitus, $H$-FABP heart-type fatty acid-binding protein, $H R s$ hazard ratios, $C l s$ confidential intervals

a Adjusted for age, gender, hypertension, dyslipidemia, body mass index, current smoking, family history of CAD and Gensini score, eGFR

IGM. Data from the present study firstly indicated that $\mathrm{H}$-FABP levels were increased in patients with IGM and importantly, H-FABP was independently associated with worse clinical outcomes in CAD patients with pre-DM and DM. This result provided novel information that elevated circulating levels of $\mathrm{H}-\mathrm{FABP}$ might be a prognostic predictor of adverse events in CAD patients with mild abnormal glucose metabolism.

As is well known, DM is a worldwide disease results in poor clinical outcomes, and is associated with large health-care costs. Nowadays, pre-DM has been attracted more attention because of its close association with increased cardiovascular risks [7-11]. In our previous studies conducted by Liu et al. [9] and Jin et al. [10], patients with pre-DM were more likely to have higher CVE risk when combined with other risk such as hypertension. What's more, the myocardial injury is reported to be another health issue in diabetic patients. Several studies have provided the evidence of myocardial damage in the early asymptomatic period among patients with IGM [12-14]. Additionally, some reports also indicated that diabetic patients could have heart damage in results of its complications like diabetic cardiomyopathy [15, 


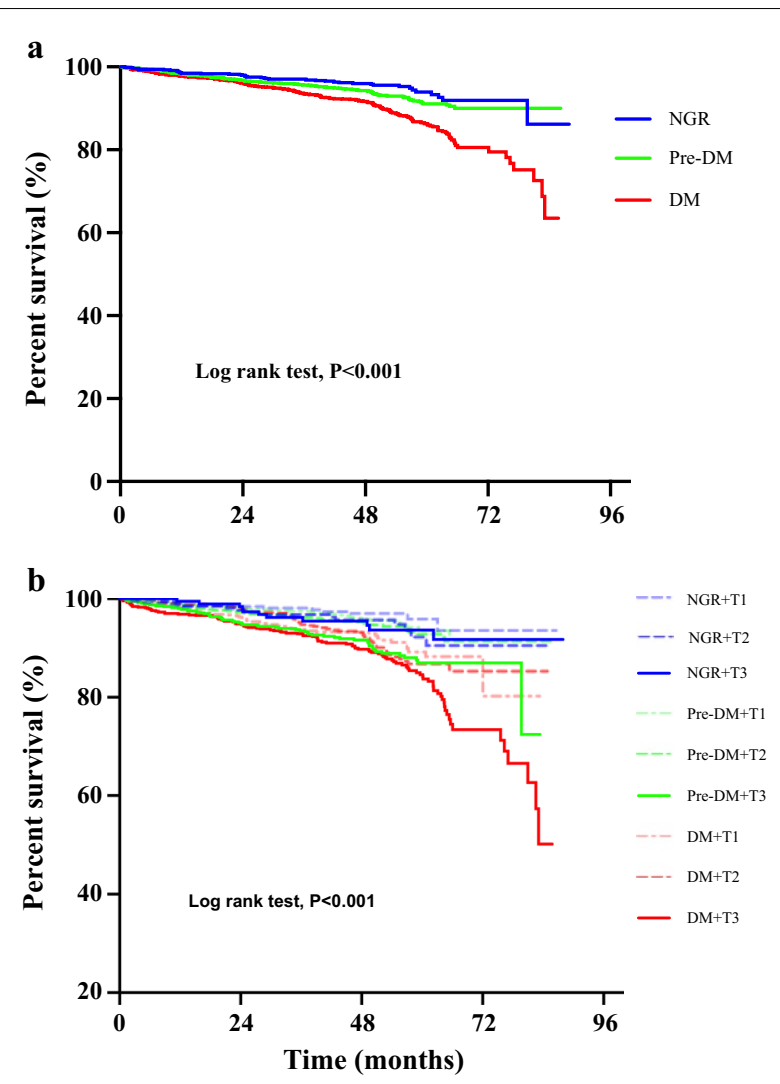

Fig. 2 Kaplan-Meier survival analysis. a Showed the Kaplan-Meier survival curves of cardiovascular event in according to status of glucose metabolism; b showed the Kaplan-Meier survival curves in 9 subgroups according to the Heart-type fatty acid-binding protein (H-FABP) tertiles and status of glucose metabolism. NGR normal glucose regulation, Pre-DM pre-diabetes mellitus, DM diabetes mellitus

16]. Therefore, a further understanding of the cardiovascular risk associated with IGM will help to risk stratification and preventive strategies in pre-diabetic patients.

$\mathrm{H}$-FABP is a small $(15 \mathrm{kDa})$ cytoplasmic protein which transfers free fatty acids from the plasma membrane in cardiomyocytes. It can be rapidly released into circulation in cases of myocardial injury and is shown to be more sensitive than myoglobin and cardiac troponins $[19,22,30]$. Indeed, H-FABP is a newly identified biomarker for acute myocardial damage and an independent predictor of adverse cardiac events [19-22]. In addition, previous studies have also shown that H-FABP levels increased in patients with several vascular diseases, and also in MetS patients with IGM [13, 14, 28]. For instance, Akbal et al. [13] reported that serum H-FABP levels were significantly higher in diabetic patients with MetS than patients without diabetic MetS, indicating its promise as a marker for detection of cardiac injury during the early asymptomatic period in diabetic patients. Another study from provided that patients with insulin resistance and MetS tended to have higher H-FABP levels, suggested that the early stages of metabolic disorder might be exposed to myocardial damage and susceptible to silent heart failure [14]. In addition, Basak et al. [28] found $\mathrm{H}$-FABP levels were increased in patients with impaired glucose metabolism, and serum H-FABP levels were positively correlated with carotid artery intima-media thickness, an intermediate phenotype for early atherosclerosis. These studies showed that serum H-FABP measurements might be used for determination of subclinical myocardial injury or subclinical atherosclerosis in diabetic patients. Therefore, we hypothesized that H-FABP could also be a useful marker for predicting the clinical outcomes in high-risk population of diabetic patients with CAD.

In the present study, we conducted a multicenter, prospective cohort with a follow-up period for up to 7.1 years to explore the prognostic role of H-FABP in CAD patients with IGM. Firstly, H-FABP levels appeared to be increased in patients with pre-DM and DM compared with normal group. There was also a significantly elevation of H-FABP levels in patients with CVEs in comparison to ones without CVEs. The hypothesized mechanism underlying the elevation of H-FABP in CAD patients with IGM has not been thoroughly studied. In a previous study of experimental diabetic model, it was reported that the H-FABP content of rat heart was marked increased, which might cause faster utilization of fatty acid in the diabetic heart [31]. Besides, diabetic patients could have structural and/or functional modifications in the myocardial tissue such as lacking of insulin sensitivity and glucose assimilation. As a compensatory mechanism, H-FABP may increase when fatty acid uptake increases in heart to supply more adenosine triphosphate (ATP) $[15,16]$. On the other hand, there is evidence that abnormal of cardiac microvascular circulation caused by metabolic disorders might induce cardiomyocyte injury and impair cardiac function [32]. Other causes such as inflammation, oxidative stress, and apoptosis increased the permeability of cardiomyocyte, contributed to the release and serum elevation of H-FABP levels in patients with cardiac damage [33]. These plausible evidences may be the explanations why H-FABP elevated in CAD patients with IGM.

In literature, the development and progression of atherosclerotic disease is modulated by many cardio-metabolic risk factors. Interestingly, in this study, we found no difference of the CVE incidence between patients with NGR and ones with pre-DM (5.6\% vs $6.6 \%, \mathrm{p}>0.05)$. When the glucose metabolism status was incorporated in H-FABP stratification, data revealed that the higher tertile of H-FABP patients were associated with higher 
risk of CVEs in pre-DM (adjusted HR: 1.855, 95\% CIs $1.076-3.214, p=0.033$ ), suggesting that H-FABP could be an independently index of adverse outcomes in CAD patients with pre-DM. To sum up, we not only analyzed the prognosis of H-FABP, but also further demonstrated the impacts of elevated H-FABP levels plus different glucose metabolic status. As the main novel findings of our study, when status of glucose metabolism was incorporated in H-FABP stratification, patients in the highest level of H-FABP group were associated with higher risk of CVEs in both pre-DM group (adjusted hazard ratio [HR]: 1.855, 95\% confidential intervals [CIs] 1.0763.214; $\mathrm{p}=0.033$ ) and DM (adjusted HR: $2.560,95 \% \mathrm{CIs}$ 1.409-4.650; $\mathrm{p}=0.002$ ). These findings indicated that the measurement of H-FABP might be suitable to predict the occurrence of myocardial injury and clinical events in patients with IGM.

There were several limitations in the current study. Firstly, this was an observational and prospective study, only association but not casual link could be determined. Secondly, we measured H-FABP once at baseline and have not compared with other traditional cardiac biomarkers. Thirdly, we did not assess all of the metabolic factors and parameters of insulin resistance due to the features of patients in our study. More studies may be needed to confirm our findings.

\section{Conclusions}

Our study, for the first time to our knowledge, demonstrated that H-FABP was a useful predictor for adverse clinical outcomes in pre-diabetic patients with CAD, suggesting that elevation of $\mathrm{H}$-FABP might provide prognostic information in CAD patients with mild abnormal glucose metabolism.

\section{Supplementary information}

Supplementary information accompanies this paper at https://doi. org/10.1186/s12933-020-0992-0.

Additional file 1: Table S1. Baseline characteristics in study patients with and without events. Table S2. H-FABP levels and glucose metabolism status in relation to cardiovascular events.

\section{Abbreviations}

H-FABP: Heart-type fatty acid-binding protein; CAD: Coronary artery disease; NGR: Normal glucose regulation; IGM: Impaired glucose metabolism; DM: Diabetes mellitus; CVE: Cardiovascular events; MetS: Metabolic syndrome; CAG : Coronary angiography; HbA1c: Hemoglobin A1c; MI: Myocardial infarction; CRV: Coronary revascularization.

\section{Acknowledgements}

None.

\section{Authors' contributions}

$\mathrm{H}-\mathrm{WZ}$ analyzed data and wrote the manuscript. H-WZ, J-LJ, Y-XC contributed to data interpretation and the editing of the manuscript. H-WZ, J-LJ, Y-XC, $\mathrm{H}-\mathrm{HL}, \mathrm{YZ}$ were responsible for study design and collection of study data.
Y-LG, N-QW, YG, R-XX, Q-H, Y-FL, C-JC, GL, QD, JS contributed to recruitment of patients and data collection, J-JL designed the study and contributed to critically revising the manuscript. All the authors reviewed the manuscript. All authors read and approved the final manuscript.

\section{Funding}

This study was partly supported by Capital Health Development Fund (201614035) and CAMS Innovation Fund for Medical Sciences (2016-I2M-1011), Fundamental Research Funds for the Central Universities (2018-F05), and Youth Research Fund of Peking Union Medical College (2018-XHQN03).

\section{Availability of data and materials}

The datasets used and analyzed during the current study are available from the corresponding author on reasonable request.

\section{Ethics approval and consent to participate}

Approvals of the local ethics committees were obtained at all sites and the informed written consents were obtained from enrolled patients. This study complied with the Declaration of Helsinki and was approved by the hospital ethical review board (FuWai Hospital and National Center for Cardiovascular Diseases, Beijing, China).

\section{Consent for publication}

Not applicable.

\section{Competing interests}

The authors declare that they have no competing interests.

\section{Author details}

${ }^{1}$ State Key Laboratory of Cardiovascular Disease, Fu Wai Hospital, National Center for Cardiovascular Diseases, Chinese Academy of Medical Sciences and Peking Union Medical College, No 167 BeiLiShi Road, XiCheng District, Beijing 100037, China. ${ }^{2}$ Department of Cardiology, Xuanwu Hospital, Capital Medical University, Beijing, China. ${ }^{3}$ Department of Cardiology, Beijing Anzhen Hospital, Capital Medical University, Beijing, China.

Received: 16 December 2019 Accepted: 22 January 2020

Published online: 10 February 2020

\section{References}

1. Bonaca MP, Gutierrez JA, Cannon C, et al. Polyvascular disease, type 2 diabetes, and long-term vascular risk: a secondary analysis of the IMPROVEIT trial. Lancet Diabetes Endocrinol. 2018;6:934-43.

2. Emerging Risk Factors C, Sarwar N, Gao P, et al. Diabetes mellitus, fasting blood glucose concentration, and risk of vascular disease: a collaborative meta-analysis of 102 prospective studies. Lancet. 2010;375:2215-22.

3. Cosentino F, Grant PJ, Aboyans V, et al. 2019 ESC guidelines on diabetes, pre-diabetes, and cardiovascular diseases developed in collaboration with the EASD. Eur Heart J. 2019;41(2):255-323.

4. American Diabetes A. Diagnosis and classification of diabetes mellitus. Diabetes Care. 2011;34(Suppl 1):S62-9.

5. Tuomilehto J. Definitions of intermediate hyperglycaemia and progression to type 2 diabetes. Lancet Diabetes Endocrinol. 2019;7:243-5.

6. Gong Q, Zhang P, Wang J, et al. Morbidity and mortality after lifestyle intervention for people with impaired glucose tolerance: 30 -year results of the Da Qing diabetes prevention outcome study. Lancet Diabetes Endocrinol. 2019;7:452-61.

7. Selvin E, Steffes MW, Zhu H, et al. Glycated hemoglobin, diabetes, and cardiovascular risk in nondiabetic adults. N Engl J Med. 2010;362:800-11.

8. Wang L, Gao P, Zhang M, et al. Prevalence and ethnic pattern of diabetes and prediabetes in China in 2013. JAMA. 2017;317:2515-23.

9. Liu HH, Cao YX, Li S, et al. Impacts of prediabetes mellitus alone or plus hypertension on the coronary severity and cardiovascular outcomes. Hypertension. 2018;71:1039-46.

10. Jin JL, Cao YX, Zhang HW, et al. Lipoprotein(a) and cardiovascular outcomes in patients with coronary artery disease and prediabetes or diabetes. Diabetes Care. 2019;42:1312-8.

11. Shahim B, De Bacquer D, De Backer G, et al. The prognostic value of fasting plasma glucose, two-hour postload glucose, and $\mathrm{HbA} 1 \mathrm{c}$ in patients 
with coronary artery disease: a report from EUROASPIRE IV: a survey from the European Society of Cardiology. Diabetes Care. 2017;40:1233-40.

12. Rubin J, Matsushita K, Ballantyne CM, et al. Chronic hyperglycemia and subclinical myocardial injury. J Am Coll Cardiol. 2012;59:484-9.

13. Akbal E, Ozbek M, Gunes F, et al. Serum heart type fatty acid binding protein levels in metabolic syndrome. Endocrine. 2009;36:433-7.

14. Narumi T, Shishido T, Kiribayashi N, et al. Impact of insulin resistance on silent and ongoing myocardial damage in normal subjects: the Takahata study. Exp Diabetes Res. 2012;2012:815098.

15. Lorenzo-Almoros A, Tunon J, Orejas M, et al. Diagnostic approaches for diabetic cardiomyopathy. Cardiovasc Diabetol. 2017;16:28.

16. Lorenzo-Almoros A, Hang T, Peiro C, et al. Predictive and diagnostic biomarkers for gestational diabetes and its associated metabolic and cardiovascular diseases. Cardiovasc Diabetol. 2019;18:140.

17. Ye $X D, H e Y$, Wang $S$, et al. Heart-type fatty acid binding protein (H-FABP) as a biomarker for acute myocardial injury and long-term post-ischemic prognosis. Acta Pharmacol Sin. 2018;39:1155-63.

18. Pyati AK, Devaranavadagi BB, Sajjannar SL, et al. Heart-type fatty acid binding protein: a better cardiac biomarker than CK-MB and myoglobin in the early diagnosis of acute myocardial infarction. J Clin Diagn Res. 2015;9:BC08-11.

19. Collinson P, Gaze D, Goodacre S. Comparison of contemporary troponin assays with the novel biomarkers, heart fatty acid binding protein and copeptin, for the early confirmation or exclusion of myocardial infarction in patients presenting to the emergency department with chest pain. Heart. 2014;100:140-5.

20. Suzuki M, Hori S, Noma S, Kobayashi K. Prognostic value of a qualitative test for heart-type fatty acid-binding protein in patients with acute coronary syndrome. Int Heart J. 2005;46:601-6.

21. O'Donoghue M, de Lemos JA, Morrow DA, et al. Prognostic utility of heart-type fatty acid binding protein in patients with acute coronary syndromes. Circulation. 2006;114:550-7.

22. Viswanathan K, Kilcullen N, Morrell C, et al. Heart-type fatty acid-binding protein predicts long-term mortality and re-infarction in consecutive patients with suspected acute coronary syndrome who are troponinnegative. J Am Coll Cardiol. 2010;55:2590-8.

23. Setsuta $K$, Seino $Y$, Mizuno K. Heart-type fatty acid-binding protein is a novel prognostic marker in patients with essential hypertension. Int J Cardiol. 2014;176:1323-5.
24. Langer M, Forkmann M, Richter U, et al. Heart-type fatty acid-binding protein and myocardial creatine kinase enable rapid risk stratification in normotensive patients with pulmonary embolism. J Crit Care. 2016;35:174-9.

25. Wunderlich MT, Hanhoff T, Goertler M, et al. Release of brain-type and heart-type fatty acid-binding proteins in serum after acute ischaemic stroke. J Neurol. 2005;252:718-24.

26. Hoffmann U, Espeter F, Weiss C, et al. Ischemic biomarker heart-type fatty acid binding protein (hFABP) in acute heart failure - diagnostic and prognostic insights compared to NT-proBNP and troponin I. BMC Cardiovasc Disord. 2015;15:50.

27. Komamura K, Sasaki T, Hanatani A, et al. Heart-type fatty acid binding protein is a novel prognostic marker in patients with non-ischaemic dilated cardiomyopathy. Heart. 2006;92:615-8.

28. Karbek B, Ozbek M, Bozkurt NC, et al. Heart-type fatty acid binding protein (H-FABP): relationship with arterial intima-media thickness and role as diagnostic marker for atherosclerosis in patients with impaired glucose metabolism. Cardiovasc Diabetol. 2011;10:37.

29. Levey AS, Stevens LA, Schmid CH, et al. A new equation to estimate glomerular filtration rate. Ann Intern Med. 2009;150:604-12.

30. Kim KS, Lee HJ, Kim K, et al. Heart-type fatty acid binding protein as an adjunct to cardiac troponin-I for the diagnosis of myocardial infarction. J Korean Med Sci. 2011;26:47-52.

31. Glatz JF, van Breda E, Keizer HA, et al. Rat heart fatty acid-binding protein content is increased in experimental diabetes. Biochem Biophys Res Commun. 1994;199:639-46.

32. Di Carli MF, Janisse J, Grunberger G, Ager J. Role of chronic hyperglycemia in the pathogenesis of coronary microvascular dysfunction in diabetes. J Am Coll Cardiol. 2003;41:1387-93.

33. Monnier L, Mas E, Ginet C, et al. Activation of oxidative stress by acute glucose fluctuations compared with sustained chronic hyperglycemia in patients with type 2 diabetes. JAMA. 2006;295:1681-7.

\section{Publisher's Note}

Springer Nature remains neutral with regard to jurisdictional claims in published maps and institutional affiliations.
Ready to submit your research? Choose BMC and benefit from:

- fast, convenient online submission

- thorough peer review by experienced researchers in your field

- rapid publication on acceptance

- support for research data, including large and complex data types

- gold Open Access which fosters wider collaboration and increased citations

- maximum visibility for your research: over $100 \mathrm{M}$ website views per year

At BMC, research is always in progress.

Learn more biomedcentral.com/submissions 